CUADERNOS DE ESTUDIOS GALLEGOS, LIX Núm. 125 (enero-diciembre 2012), págs. 233-244

ISSN: 0210-847 X

DOI: $10.3989 /$ ceg.2012.125.344

\title{
"UN ESCLAVO QUE SE LLAMA ANTONIO": VENTA DE DOS ESCLAVOS ASIÁTICOS EN GALICIA A INICIOS DEL SIGLO XVII
}

Caroline Ménard

Université de Montréal 


\title{
«UN ESCLAVO QUE SE LLAMA ANTONIO»: VENTA DE DOS ESCLAVOS ASIÁTICOS EN GALICIA A INICIOS DEL SIGLO XVII
}

\begin{abstract}
RESUMEN
La esclavitud era conocida en la Península Ibérica desde la Antigüedad y durante la Época Moderna y no se limitó a la sumisión de personas de origen africana. Este artículo trata de la venta de dos esclavos de origen asiático, Antonio y Domingo, en el puerto de Vigo en 1603; en él se analiza la ruta emprendida por éstos, el papel desempeñado por los marineros portugueses de la Carreira da India como vendedores, así como su origen y precio. Antonio y Domingo representan una minoria dentro del conjunto de los esclavos viviendo en ese momento en Galicia, pero su presencia es un ejemplo ilustrativo de la dinámica vigente en la época.
\end{abstract}

PALABRAS ClaVE: esclavos asiáticos, Galicia, Estado da India, siglo XVII.

\section{«UN ESCRAVO QUE SE CHAMA ANTONIO» : VENTA DE DOUS ESCRAVOS ASIÁTICOS EN GALICIA NO INICIO DO SÉCULO XVII}

\section{RESUMO}

A escravitude era coñecida na Península Ibérica dende a Antigüidade e durante a Época Moderna e non se limitou a sumisión de persoas de orixe africana. Este artigo trata da venda de dous escravos de orixe asiática, Antonio e Domingo, no porto de Vigo no 1603. No artigo analízase a ruta realizada por estes e a súa orixe e prezo, así como o papel xogado polos mariñeiros portugueses na Carreira da India como vendedores. Antonio y Domingo representan unha corrente minoritaria dentro do conxunto dos escravos que viven en Galicia nesta época, mais a sua presencia é un bon exemplo da dinamica vivida nesta época.

PALABRAS ClaVE: escravos asiáticos, Galicia, Estado da India, século XVII.

\section{«A SLAVE NAMED ANTONIO»: TWO ASIAN SLAVES SALES IN GALICIA AT THE BEGINNING OF THE $17^{\mathrm{TH}}$ CENTURY}

\begin{abstract}
Slavery has existed in the Iberian Peninsula since the Antiquity and up to the Modern Era - and moreover, it was not restricted to the submission of people coming from Africa. This paper will look at the sale of two slaves originally from Asia, Antonio and Domingo, in 1603 in the port of Vigo - it will explore their journey, the role of the Carreira da India Portuguese mariners as sailors, their origin and sale price. Antonio and Domingo might represent a minority compared to all the slaves living at that time in Galicia, but their difference is a rich illustration of the process as it was then working.
\end{abstract}

KeY woRDS: Asian Slaves, Galicia, Estado da India, $17^{\text {th }}$ Century. 
Recibido/Received: 13/04/2012

Aceptado/Accepted: 07/09/2012

$\mathrm{H}$ acia finales del siglo XV e inicios del XVI, el origen y volumen de los esclavos en Castilla cambian notablemente, debido a la expansión portuguesa por las costas africanas con la que se inicia nuevas redes de redistribución tanto de productos como de hombres. Fenómeno bien estudiado y mejor conocido para las ciudades de la parte meridional de la península, algunos sostienen que, extrapolando a falta de datos para el conjunto de España, la población esclava podía alcanzar 100000 personas o más hacia finales del siglo XVI ${ }^{1}$.

Al igual que el resto de la península, Galicia contaba entre su población con esclavos negros, aunque todavía sea difícil determinar su número. Desde inicios del siglo XVI, nos llegan noticias dispersas sobre la existencia de algunos de ellos a través de documentos de compraventa entre particulares, últimas disposiciones de amos, manumisión, etc, en resumen, recogidas en el espectro de acuerdos comerciales existentes en la época. Sobre el recorrido exacto de ellos poco se sabe, pero la proximidad con Portugal, recordemos actor importante en el abastecimiento de esclavos africanos, parece ser un hecho determinante al verse involucrados muchos ciudadanos de este reino en las actas de venta ${ }^{2}$.

La presencia de esclavos en la Península Ibérica y en Galicia en esta época no es, como ya se ha visto, ninguna novedad. Sin embargo a menudo se olvida la variedad de la procedencia de éstos, limitándonos a considerar sólo los esclavos de estratos africanos o de sus descendientes, cuando en realidad también

\footnotetext{
${ }^{1}$ Para una bibliografía amplia sobre la esclavitud en la Península Ibérica ver Alessandro Stella, "Bibliographie choisie sur l'esclavage", Nuevo Mundo, Mundos Nuevos, [en línea], disponible en $<$ http://nuevomundo.revues.org/492> [Consulta: 26/09/2011].

2 Pablo Peréz Constanti, Notas viejas galicianas, Vigo, Imprenta de los Sindicatos Católicos, 1925, págs. 279-285. Agradezco a la Biblioteca de Orense por facilitarme el acceso a esta publicación.
} 
moriscos, turcos, berberiscos formaron parte del trabajo servil, tanto en la Edad Media, como en la Época Moderna ${ }^{3}$.

Con el movimiento de las exploraciones, descubrimientos y conquista de nuevos territorios, el origen de los esclavos se diversificó. Después de la llegada de Colón a América, algunos nativos fueron llevados hasta la península como esclavos, aunque rápidamente esta trata fue condenada ${ }^{4}$. En el caso gallego, los primeros contactos con la realidad y pobladores del Nuevo Mundo se realizó durante algún tiempo a través de la Casa de Especería, institución localizada en La Coruña. Una cincuentena de amerindios, originarios de América del Norte, llegó a estas orillas, en la expedición de Esteban Gómez, realizada en 1525, aunque éstos no pudieron ser vendidos como esclavos al ser considerados como súbditos del rey, aunque gozaron de una libertad restringida. Menos suerte tuvo una veintena de nativos procedentes del Brasil, tripulación que desembarcó al puerto herculino a bordo de la expedición de Loaysa, en 1527, y que fue vendida como esclavos al proceder de territorios portugueses ${ }^{5}$. A pesar de la prohibición de someter a los habitantes de las recién descubiertas tierras americanas, otros "indios" conocerán la esclavitud después de una larga travesía que les trajo desde las Indias Orientales.

En comparación con la trata y tráfico de esclavos que existieron en el Atlántico, cuyo interés y volumen fueron importantes, muchas incógnitas perduran sobre lo que sucedió en el océano Índico ${ }^{6}$. El estudio del volumen, destino y suerte de los esclavos procedentes de este área supone un desafío archivístico cuyos rastros documentales se encuentran dispersos entre diversas instituciones europeas, africanas y asiáticas. Se posee una información discontinua que puede ser interpretada a la vez como una característica subyacente a esta fuente de trabajo servil y como indicador de la disponibilidad de esclavos en correlación con épocas de carestías y hambrunas ${ }^{7}$. Vink por su parte adelanta otras razones para explicar este vacío: se debería en parte a que en el Océano Índico los europeos

\footnotetext{
3 Alessandro Stella, "L'esclavage en Andalousie à l'époque moderne", Annales ESC, 1 (1992), págs. $45,48,51$.

${ }^{4}$ Alessandro Stella, Histoires d'esclaves dans la péninsule ibérique, París, Éditions de l'École des Hautes Études en Sciences Sociales, 2000, pág. 65.

5 Louis-André Vigneras, "El viaje de Esteban Gomez a Norte América", Revista de Indias, 68 (1957), págs. 197-201. Constan ventas de indios procedentes de Brasil en otros lugares, como en Valencia, Vicenta Cortés, La esclavitud en Valencia durante el reinado de los Reyes Católicos, Valencia, Ayuntamiento de Valencia, 1964, pág. 60.

${ }^{6}$ Indrani ChatTerJeE, "Indian Subcontinent”, Macmillan Encyclopedia of World Slavery, 1, New York, Macmillan Reference USA, 1998, pág. 425.

7 S. Arasaratnam, "Slave Trade in the Indian Ocean in the Seventeenth Century", Mariners, Merchants and Oceans: Studies in Maritime History, New Delhi, Manohar, 1995, págs. 195, 199.
} 
no impusieron un sistema complejo, como lo establecieron entre África y el Nuevo Mundo, sino que interactuaron con los circuitos y modelos de esclavitud existentes en la región; modelos y sistemas que fueron considerados también durante mucho tiempo como menos "benignos" en comparación con el tráfico atlántico ${ }^{8}$.

Los portugueses fueron de los primeros europeos en llegar a la India, concluyendo años de largas navegaciones avanzando, reconociendo y estableciendo puestos a lo largo de las costas africanas. Algunos historiadores aseguran que los mercados internos de esclavos habían desaparecido ya en el siglo XV, aunque varios testimonios de coetáneos europeos aluden a la existencia de éstos en los puertos de la India. El hecho fue que, rápidamente, los portugueses se familiarizaron con las distintas redes, redistribuyendo nativos de todas las regiones por toda Asia, utilizando como base sus distintas fortalezas, feitorias y ciudades de lo que constituyó el dilatado Estado da India. Fue entonces cuando muchos esclavos originarios de la India, China, Bengala, Macao, incluso del Este de África, fueron sujetos a un tráfico de mediana o larga distancia, alimentando los distintos mercados de Goa, Cochin, etc, o incluso más al Este, como es el caso de los de Manila y Aceh'.

El destino final de estos esclavos no se limitó al área circundante, sino que varios de ellos llegaron a viajar en las naos del rey hasta Portugal y a veces proseguir su periplo por Europa. Ya en el siglo XVI, Lisboa poseía una amplia población esclava dejando creer a sus coetáneos que contaba más esclavos, entre ellos asiáticos, que portugueses libre ${ }^{10}$. Fue precisamente a través de portugueses como llegaron los primeros esclavos asiáticos a España, concretamente a inicios del siglo XVI; tanto en Sevilla, Valencia y Cádiz, se ha constatado su presencia $^{11}$.

Por estas mismas fechas, en 1507 concretamente, aparece un primer testimonio, escueto, sobre la presencia temporal de un joven esclavo indio, originario de Calicut, por tierras gallegas: "Fray Antonio Miracles, franciscano, presenta un negro. Antonio, de 10 años, de Calicut, que ha traído de Galicia para su servicio.

\footnotetext{
${ }^{8}$ Markus VINK, “«The World's Oldest Trade»: Dutch Slavery and Slave Trade in the Indian Ocean in the Seventeenth Century", Journal of World History, 2 (2003), págs. 133-134.

9 Jeanette PINTo, Slavery in Portuguese India, 1510-1842, Bombay, Himalaya Pub House, 1992, págs. 35-36; S. Arasaratnam, "Slave Trade in the Indian Ocean...», págs. 196-197; Tatiana SeiJas, “The Portuguese Slave Trade to Spanish Manila: 1580-1640”, Itinerario, 1 (2008), págs. 19-38.

10 Jeannette PinTo, Slavery in Portuguese India..., págs. 19, 46.

11 Vicente Graullera Sanz, La esclavitud en Valencia en los siglos XVI y XVII, Valencia, Instituto Valenciano de Estudios Históricos, 1978, pág. 134; Vicenta CoRTés, La esclavitud en Valencia durante el reinado..., págs. 60-61, 428; Alfonso Franco SILVA, La esclavitud en Andalucía, 14501550, Granada, Universidad de Granada, 1992, pág. 40.
} 
Estimado en 20 lbs." ${ }^{12}$. El pequeño Antonio no será el único, ya que dos nuevos documentos, fechados casi un siglo después, nos remiten a esta trata minoritaria y menos conocida, aludiendo a la venta de dos esclavos orientales, ofreciéndonos en la misma ocasión más detalles en cuanto a las circunstancias que rodean su presencia en Galicia.

Como señalamos anteriormente, la proximidad a Portugal permitió a menudo la introducción en Galicia de esclavos negros a través de la venta entre particulares. Como es lógico pensar, el mismo papel pudieron jugar éstos en la aparición de esclavos asiáticos por tierras gallegas y así lo demuestran dos escrituras notariales, ambas redactadas en Vigo, en el otoño de 1603.

El primer documento nos remite a una relación contractual que tiene lugar entre Juan González y Antonio Núñez Vela, a finales de septiembre de 1603, sobre la persona de Antonio.

\begin{abstract}
"En la villa de Vigo, a veinte y nueve días del mes de septiembre de mil y seiscientos y tres años, por ante mi escribano y testigo pareció presente Juan Gonçalez, marinero de la nave de la India, vecino de la ciudad de Lisboa, morador en la Calçada del Congrio al Poço nuevo reino de Portugal, y dijo que en aquella vía que de derecho mejor lugar haya vendía y daba en venta a Antonio Núñez Bela, alférez de maestre de campo, un esclavo que se llama de nombre Antonio, de edad de hasta diez anos poco mas o menos, de casta cumbrin, cabello llano, negro, de poca frente y los dos dientes delanteros grandes, el cual tubo de Gaspar de Matos Meino, de la ciudad de Cochin, Reino de la India de Portugal, el cual dijo vendía el dicho esclavo al dicho Antonio Núñez Vela por suyo propio con todas las tachas buenas y malas que el dicho Antonio esclavo había y tenía, pudiese tener a lo adelante y según y de la manera que el dicho Gaspar de Matos se lo había vendido en precio y cuantía de doscientos y cincuenta reales de plata castellanos..."13.
\end{abstract}

El segundo documento, de inicio de octubre del mismo año, escrito ante el mismo notario en Vigo, consigna la venta del esclavo llamado Domingo realizada entre Roque Fernández Cantero y Juan Ochoa y Turrioz.

"En la villa de Vigo, a dos días del mes de octubre de mil y seiscientos y tres años, por ante mi escribano y testigo pareció presentes Roque Fernández Cantero, marinero de las naves de la India de Portugal que al presente están surtas en la ría de esta dicha villa, y dijo que en la mejor

\footnotetext{
12 Vicenta CoRTés, La esclavitud en Valencia durante el reinado..., pág. 350.

13 Archivo Histórico Provincial de Pontevedra, protocolos notariales, Blas de Caldas, leg. 2190, fols. 36-37, Vigo, 29 de septiembre de 1603.
} 
manera y vía que de derecho haya lugar de dar vendía y daba en venta perpetua a Juan Ochoa y Turrioz, vecino de la ciudad de La Coruña, que estaba presente, para él y sus herederos y sucesores, es a saber que le daba en esta dicha venta a Domingo moreno su esclavo, de casta bengala, que tiene por señal el cabello corredio, el cual Domingo esclavo dijo le vendía por suyo propio y según y de la manera que lo había comprado en la ciudad de Cochin, Reino de la India, a Manuela López, viuda, vecina de la dicha ciudad de Cochin, el cual dicho esclavo vendió al dicho Ochoa en precio y cuantía de cuatrocientos y cincuenta (...) de plata castellanos ..." ${ }^{14}$.

En ambos casos el vendedor es un marinero portugués de la Carreira da India que está de paso en la villa de Vigo por encontrarse allí las naves del rey. De hecho, dos de estas naves, partidas de un grupo de seis en marzo de 1602, arribaron en el tornaviaje a Vigo por causa de tormenta y descargaron en la vi$1 \mathrm{a}^{15}$. Así pues queda patente el importante papel que jugaron los componentes de la tripulación en el tráfico de esclavos, quienes se integraban en redes mucho más amplias.

Al contrario, poca información tenemos acerca de los compradores si no es su nombre, su ocupación en el caso de Antonio Núñez Vela quien era alférez de campo, y su lugar de residencia como el de Juan Ochoa Turrioz, quien vivía en la villa herculina. Sin embargo, podemos constatar que estas transacciones directas, sin presencia de algún intermediario, se realizan en un núcleo urbano, dotado de un puerto, y que el interés por esta mercancía no se limita a su entorno inmediato.

En cuanto al origen de Antonio y Domingo, tenemos la suerte de tener más detalles e informaciones, aunque sean parciales, ya que a menudo los esclavos asiáticos pueden estar catalogados de forma genérica como "chino" o "indio chino" ". Domingo, cuya edad desconocemos, provenía de Bengala. De forma no oficial, los portugueses estuvieron presentes en Bengala, practicando comercio, integrándose en las redes comerciales existentes, casándose con nativas ${ }^{17}$. Entre sus actividades en la bahía del mismo nombre figuraba la captura de naturales que ulteriormente vendían como esclavos a otros comerciantes. A finales

\footnotetext{
14 Ibíd., fols. 34-35, Vigo, 2 de octubre de 1603.

15 Se tratan de las naves Conceição (capitán Diego Pais de Castelo Branco) y San Roque (capitán Constantino de Menelau). Maria Herminia Maldonado, Relação das náos e armadas da India com os successos dellas que se puderam saber, para noticia e instrucção dos curiozos, e amantes da historia da India, Coimbra, Biblioteca Geral da Universidade de Coimbra, 1985, pág. 107.

16 Déborah Oropeza Keresey, "La esclavitud asiática en el virreinato de la Nueva España, 15651673”, Historia mexicana, 1 (2011), pág. 17.

17 M. N. Pearson, The Portuguese in India, New York, Cambridge University Press, 1987, pág. 84.
} 
del siglo XVI e inicios del siglo XVII, la expansión política y militar de los reyes de Arakan en Bengala propició la alianza con estos portugueses para saquear en las costas adyacentes y raptar gente; entre ellos muchos niños de poca edad fueron capturados a la fuerza ${ }^{18}$.

El joven Antonio está descrito como perteneciente a la casta cumbrin; quizás sea una deformación de la palabra curumbim, un grupo social inferior dentro de la sociedad india, que se dedicaba principalmente a tareas vinculadas a la agricultura y pesca ${ }^{19}$. Unos años antes de la fecha de redacción de estos documentos notariales, el holandés Van Linschoten, quien vivió unos años en Goa y trabajó para los portugueses, describió a los "corumbis" como los pobladores más endebles y pobres ${ }^{20}$.

Por desgracia, no sabemos como ambos llegaron a adquirir la condición de esclavos. Desde el siglo XVI, se legisló sobre las posibles causas del cautiverio de una persona y las autoridades eclesiásticas del Estado da India las limitaron a cinco: ser descendiente de esclava, caer entre las manos del enemigo durante una guerra justa, venderse como tal o vender su progenitura en caso de necesidad extrema y finalmente, ser declarado esclavo en su tierra a causa de algún delito cometido $^{21}$. Este marco legal no impidió los actos de piraterías, ni las capturas forzadas por parte de mercaderes, ni los tratos entre distintos intermediarios y las declaraciones fraudulentas para confirmar la legalidad de la condición de subordinación de una persona ${ }^{22}$.

Ambos esclavos fueron comprados en la ciudad de Cochin, en el suroeste de la costa de India. Esta ciudad fue de las primeras fortificadas en Asia por los portugueses, por tener un buen acceso a los cultivos de pimienta y porque era en sus inicios la capital del Estado da India, hasta que esta función recayó en Goa, situado un poco más al norte en la costa del Malabar ${ }^{23}$. Rápidamente Cochin se convirtió en un puerto relevante así como un rico y diversificado almacén para la adquisición de especias y productos varios procedentes de toda la India, Bengala, Malaca, Macao, entre ellos mercancías humanas. El cronista portugués António Bocarro, en su obra sobre el estado de las Indias Orientales, resaltó

\footnotetext{
18 S. Arasaratnam, "Slave Trade in the Indian Ocean...», págs. 197-198.

19 Sebastião Rodolfo Delgado, Glossário Luso-Asiático, Coimbra, Imprensa da Universidade 1919, pág. 338; Charles Ralph Boxer, Race Relations in the Portuguese Colonial Empire, $1415-$ 1825, London, Clarendon Press, 1963, pág. 75.

20 Jan Huyden Van Linschoten, Histoire de la navigation de Iean Hugues de Linschot Hollandais: aux Indes Orientales, Ámsterdam, Chez Evert Cloppenburgh, 1638, pág. 77.

21 Déborah Oropeza Keresey, "La esclavitud asiática en el virreinato...», págs. 21-22.

22 Tatiana Seijas, "The Portuguese Slave Trade to Spanish...”, págs. 24, 27.

23 M. N. Pearson, The Portuguese in India..., págs. 30-31.
} 
esta función de centro de redistribución de esclavos: «A principal partte pera onde se navegava de Cochin era pera a China e Manilha com muitos escravos pera Manilha...» ${ }^{24}$. Del resto, la sociedad portuguesa en estas latitudes empleaba mucha mano de obra esclava para su servicio personal y efectuar diversas tareas, considerando su número como un símbolo de su estatus y prestigio social ${ }^{25}$. Esta realidad implicaba por lo tanto la existencia de una demanda y de un mercado interno para la adquisición de servidumbre.

En cuanto al precio de ambos esclavos, nos faltan datos comparativos, dentro del contexto gallego, para poder apreciar en su justo valor su significado, tanto entre esclavos de la misma procedencia como de otras, además de su edad, sexo y habilidades. Datos de la primera mitad del siglo XVI sobre precios de venta de esclavos en La Palma hablan de cuantías superiores a 550 reales por esclavos africanos de corta edad, quienes en general alcanzaban sumas inferiores a los adultos considerados más aprovechables ${ }^{26}$; cantidades que distan mucho de nuestro caso. Esta realidad fue establecida también en la ciudad de Sevilla a inicios del siglo XVI, donde listados de precios de esclavos demuestran que los esclavos indios estaban entre los menos valorados por sus pocas aptitudes para trabajo físico, siendo más baratos que el resto ${ }^{27}$; situación opuesta vivida en Portugal, donde éstos mismos, pero sobre todo los esclavos japoneses y chinos, gozaban de una cierta consideración y estima ${ }^{28}$. En los albores del siglo XVII, en el caso de Galicia, ¿cuál eran su situación?; ¿acaso el exotismo oriental conllevaba un cierto atractivo para sus futuros dueños? o bien ¿eran menospreciados frente a sus hermanos de infortunio de origen africano?

Es posible que más esclavos oriundos de Asia pisaran las tierras del Reino de Galicia durante este periodo. La casualidad de la arribada de una nao del rey o de algún cargo privado de la Carreira da India no es única, se conocen más casos, concretamente hacia finales del siglo XVI e inicios del siglo XVII. En

\footnotetext{
${ }^{24}$ António Bocarro, O livro das plantas de todas as fortalezas, cidades e povoaçoes do Estado da India oriental, Lisboa, Imprensa Nacional - Casa da Moeda, 1992, pág. 206; esta página corresponde a los folios 116-116v del manuscrito escrito en 1635.

25 Charles Ralph Boxer, Portuguese Society in the Tropics. The Municipal Councils of Goa, Macao, Bahia, and Luanda, 1510-1800, Madison, University of Wisconsin Press, 1965, pág. 39. Algunos de los grabados incluidos en la obra de Van Linschoten retratan escenas cotidianas donde se notan la presencia de esclavos y éste afirmaba que algunos portugueses podían tener entre veinte y treinta de ellos para su servicio y algunas damas ricas hasta 300 .

${ }^{26}$ Fernando Bruquetas de Castro y Luisa Toledo Bravo de Laguna, "La esclavitud en La Palma 1600-1650", Actas del XIII Coloquio de Historia Canario-Americana, [CD-ROM], Las Palmas de Gran Canaria, Cabildo Insular de Gran Canaria, 2000, pág. 2266.

${ }^{27}$ Alfonso Franco Silva, La esclavitud en Andalucía..., pág. 84.

28 Ivana Elbl, "Slavery in Portugal", Macmillan Encyclopedia of World Slavery, 2, New York, Macmillan Reference USA, 1998, pág. 737.
} 
noviembre de 1593, el barco San Pantaleão arribó en Vigo para regresar solo en febrero del año siguiente a Lisboa; en 1607 otro barco llegó al puerto vigués a consecuencia de una tormenta. Finalmente, en 1625, se tiene noticia de la presencia de otros dos barcos, esta vez en La Coruña, después que el rey ordenara el cambio de destino por temor al ataque de una armada inglesa ${ }^{29}$. Cada uno de estos barcos podía llevar a bordo, al margen de otras mercancías muy valiosas como especias, telas, etc, un centenar de esclavos o más ${ }^{30}$.

Por ello podemos suponer que, como en el caso de la venta de esclavos africanos, los tratos entre vecinos de ambos reinos pudieron facilitar la introducción de nuevos esclavos. Por aquel entonces, ciudades como Lisboa poseía numerosos esclavos entre ellos "chinos" e "indios" ${ }^{31}$. Finalmente, otros pudieron llegar hasta la península, siguiendo a sus amos procedentes de alguna posesión americana, como del virreinato de Nueva España, territorio que mantenía un vínculo directo con Asia a través de las Filipinas ${ }^{32}$.

En conclusión, podemos constatar que Galicia experimenta similitudes con la dinámica esclavista imperante en el resto de la península, incluyendo también la presencia de esclavos asiáticos, y eso desde inicios del siglo XVI. La vecindad con el Reino de Portugal otorga a éste un papel relevante en el abastecimiento de esta mercancía humana, aunque no exclusivo, y la diversidad e intensidad de este tráfico va a la par de la expansión marítima y consolidación colonial de la época.

El hallazgo de estos dos documentos no deja de ser anecdótico, se trata de una realidad aislada y probablemente minoritaria dentro lo que es el mundo de la esclavitud. Por lo tanto, nos hallamos lejos de afirmar la existencia de una cierta continuidad a partir de estos testimonios breves, ya que para ello faltan otros datos que arrojen más luz sobre las muchas sombras entorno a este particular, pero enriquecen nuestra visión general de la esclavitud en Galicia.

\footnotetext{
29 Maria Herminia Maldonado, Relação das náos e armadas da India..., págs. 95-96, 110, 140.

30 Alessandro Stella, Histoires d'esclaves..., pág. 65. El valor total de los esclavos traídos de las Indias orientales por el período 1580-1640 se estima a 216.000 cruzados, James C. BoYAJIAN, Portuguese Trade in Asia under the Habsburgs, 1580-1640, Baltimore, John Hopkins University Press, 1993, pág. 44.

31 Jeanette PinTo, Slavery in Portuguese India..., pág. 18. Según los registros parroquiales de Lisboa de entre 1570 y 1610 , entre 10 y $20 \%$ de los esclavos eran originarios de las Indias Orientales. Alessandro Stella, Histoires d'esclaves..., pág. 65.

32 Déborah Oropeza Keresey, "La esclavitud asiática en el virreinato...», pág. 35.
} 


\section{BIBLIOGRAFÍA}

Arasaratnam, S., "Slave Trade in the Indian Ocean in the Seventeenth Century", Mariners, Merchants and Oceans : Studies in Maritime History, New Delhi, Manohar, 1995, págs. 195-208.

Bocarro, António, O livro das plantas de todas as fortalezas, cidades e povoaçoes do Estado da India oriental, Lisboa, Imprensa Nacional - Casa da Moeda, 1992.

Boyajian, James C., Portuguese Trade in Asia under the Habsburgs, 1580-1640, Baltimore, John Hopkins University Press, 1993.

Boxer, Charles Ralph, Race Relations in the Portuguese Colonial Empire, 1415-1825, Oxford, Clarendon Press, 1963.

Boxer, Charles Ralph, Portuguese Society in the Tropics. The Municipal Councils of Goa, Macao, Bahia, and Luanda, 1510-1800, Madison, University of Wisconsin Press, 1965.

Bruquetas de Castro, Fernando y Luisa Toledo Bravo de Laguna, "La esclavitud en La Palma 1600-1650", Actas del XIII Coloquio de Historia Canario-Americana, [CD-ROM], Las Palmas de Gran Canaria, Cabildo Insular de Gran Canaria, 2000.

Chatterjee, Indrani “Indian Subcontinent”, Macmillan Encyclopedia of World Slavery, vol. 1, New York, Macmillan Reference USA, 1998, págs. 425-427.

Cortés, Vicenta, La esclavitud en Valencia durante el reinado de los Reyes Católicos, Valencia, Ayuntamiento de Valencia, 1964.

Delgado, Sebastião Rodolfo, Glossário Luso-Asiático, Coimbra, Imprensa da Universidade, 1919.

Elbl, Ivana, "Slavery in Portugal", Macmillan Encyclopedia of World Slavery, vol. 2, New York, Macmillan Reference USA, 1998, págs. 737-738.

Franco Silva, Alfonso, La esclavitud en Andalucía, 1450-1550, Granada, Universidad de Granada, 1992.

Graullera Sanz, Vicente, La esclavitud en Valencia en los siglos XVI y XVII, Valencia, Instituto Valenciano de Estudios Históricos, 1978.

Maldonado, Maria Herminia, Relação das náos e armadas da India com os successos dellas que se puderam saber, para noticia e instrucção dos curiozos, e amantes da historia da India, Coimbra, Biblioteca Geral da Universidade de Coimbra, 1985.

Oropeza Keresey, Déborah "La esclavitud asiática en el virreinato de la Nueva España, 15651673”, Historia mexicana, 1 (2011), págs. 5-57.

Pearson, M. N., The Portuguese in India, New York, Cambridge University Press, 1987.

Peréz Constanti, Pablo, Notas viejas galicianas, Vigo, Imprenta de los Sindicatos Católicos, 1925,3 vols.

Pinto Jeanette, Slavery in Portuguese India, 1510-1842, Bombay, Himalaya Pub House, 1992.

Seijas, Tatiana "The Portuguese Slave Trade to Spanish Manila : 1580-1640", Itinerario, 1 (2008), págs. 19-38.

Stella, Alessandro, "L'esclavage en Andalousie à l'époque moderne", Annales ESC, 1 (1992), págs. 35-63.

Stella, Alessandro, Histoires d'esclaves dans la péninsule ibérique, París, Éditions de l’École des Hautes Études en Sciences Sociales, 2000. 
Stella, Alessandro, "Bibliographie choisie sur l'esclavage", Nuevo Mundo, Mundos Nuevos, [en línea], disponible en <http://nuevomundo.revues.org/492> [Consulta: 26/09/2011].

Van Linschoten, Jan Huyden, Histoire de la navigation de Iean Hugues de Linschot Hollandais aux Indes Orientales, Ámsterdam, Chez Evert Cloppenburgh, 1638.

Vigneras, Louis-André "El viaje de Esteban Gomez a Norte América”, Revista de Indias, 68 (1957), págs. 189-207.

Vink, Markus, “«The World's Oldest Trade»: Dutch Slavery and Slave Trade in the Indian Ocean in the Seventeenth Century", Journal of World History, 2 (2003), págs. 131-177. 